\title{
Si-doped high Al-content AIGaN epilayers with improved quality and conductivity using indium as a surfactant
}

\author{
T. M. Al tahtamouni, A. Sedhain, J. Y. Lin, and H. X. Jiang ${ }^{a)}$ \\ Department of Physics, Kansas State University, Manhattan, Kansas 66506-2601, USA
}

(Received 28 January 2008; accepted 5 February 2008; published online 4 March 2008)

\begin{abstract}
Effects of indium as a surfactant for the growth of Si-doped $\mathrm{Al}_{0.75} \mathrm{Ga}_{0.25} \mathrm{~N}$ epilayers by metal organic chemical vapor deposition have been studied. It was found that the use of indium as a surfactant improved the overall material quality of these epilayers, as evidenced by decreasing the (a) density of surface pits, (b) screw dislocation density, and (c) intensity of the deep level impurity transition with increasing indium flow rate. Hall effect measurements also yielded increased conductivity and electron concentration with increasing indium flow rate. The results suggested that indium as a surfactant counteracts the incorporation of defects responsible for self-compensation for $n$-type doping, namely, cation vacancies, in high Al-content AlGaN epilayers. A correlation between the intensity of the deep level impurity transition and screw dislocation density was also established. (C) 2008 American Institute of Physics. [DOI: 10.1063/1.2890416]
\end{abstract}

AlGaN alloys are recognized as promising materials for applications in optoelectronic devices in deep ultraviolet spectral range. Highly conductive ( $p$ - and $n$-types) AlGaN alloys are essential for many device applications. Although $n$-type AlN by Si doping with a Si energy level ranging from 86 to $250 \mathrm{meV}$ has been reported, ${ }^{1-4}$ further improvements in the material quality and electrical conductivity are still needed for many device applications. One of the major difficulties in obtaining highly conductive $n$-type Al-rich AlGaN alloys is the effect of trapping of electrons by cation vacancies and their complexes. Suppressing such intrinsic defects could significantly improve the conductivity and material quality of high Al-content AlGaN alloys. ${ }^{1-10}$

Dislocations may also introduce acceptorlike centers through dangling bonds along the dislocation line. ${ }^{11}$ Deepening of the $\mathrm{Si}$ impurity level as a function of $\mathrm{Al}$ composition is another reason as to why the electrical conductivity of $n$-type $\mathrm{AlGaN}$ layers decreases when the $\mathrm{Al}$ concentration increases. ${ }^{12}$ Indium-silicon codoping in $\mathrm{Al}_{x} \mathrm{Ga}_{1-x} \mathrm{~N}$ ( $x$ $\leqslant 0.65$ ) epilayers at relatively low growth temperatures $\sim 920-950{ }^{\circ} \mathrm{C}$ has been reported to result in higher electron concentrations and lower resistivities. ${ }^{13,14}$

In this work, we studied the effects of using indium as a surfactant for the epitaxial growth of Si-doped $\mathrm{Al}_{0.75} \mathrm{Ga}_{0.25} \mathrm{~N}$ epilayers. Si-doped $\mathrm{Al}_{0.75} \mathrm{Ga}_{0.25} \mathrm{~N}$ epilayers of about $0.8 \mu \mathrm{m}$ in thickness were grown on $\mathrm{AlN} / \mathrm{SiC}$ templates by metal organic chemical vapor deposition (MOCVD). Undoped AlN epilayers with thickness of $\sim 1 \mu \mathrm{m}$ were first grown on the $c$-plane (001) of $\mathrm{SiC}$ substrates as templates followed by the growth of $0.8 \mu \mathrm{m}$ Si-doped $\mathrm{Al}_{0.75} \mathrm{Ga}_{0.25} \mathrm{~N}$ epilayers. Trimethylaluminum, trimethylgallium, trimethylindium (TMIn), and ammonia were used as sources for aluminum, gallium, indium, and nitrogen, respectively. For the silicon dopants, silane $\left(\mathrm{SiH}_{4}\right)$ was transported into the reactor. An undoped AlN epilayer template plays an important role to reduce dislocations in the subsequent Si doped AlGaN layer. ${ }^{15}$ During the growth of Si-doped $\mathrm{Al}_{0.75} \mathrm{Ga}_{0.25} \mathrm{~N}$ layer, TMIn was introduced into the gas stream. TMIn flow rate was intentionally varied as $0,18,24$, and $30 \mathrm{ml} / \mathrm{min}$ (which corresponds to 0 ,

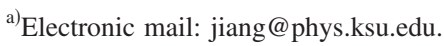

1.6, 2.1, and $2.6 \mu \mathrm{mol} / \mathrm{min}$ ) while keeping other growth conditions the same.

In addition to a significantly increased doping efficiency, it was found that the flow of indium during the growth also allows for the direct deposition of a crack-free $0.8 \mu \mathrm{m}$ thick Si-doped $\mathrm{Al}_{0.75} \mathrm{Ga}_{0.25} \mathrm{~N}$ epilayer over a $1 \mu \mathrm{m}$ thick $\mathrm{AlN}$ template on $c$-plane $\mathrm{SiC}$ substrate. Atomic force microscopy (AFM) images clearly reveal that indium as a surfactant plays a role in eliminating the defects by reducing the surface pits density. Room temperature (RT) photoluminescence (PL) measurements ${ }^{16}$ show a clear correlation between the emission intensity of the defect related transition and indium flow rate. X-ray diffraction (XRD) shows a correlation between indium flow rate and screw dislocation density through the reduction of the full width at half maximum (FWHM) of the (002) rocking curves.

Figure 1 compares the AFM images of the surfaces of these epilayers, with the TMIn flow rates of (a) 0, (b) 18, (c) 24 , and (d) $30 \mathrm{ml} / \mathrm{min}$. The measured root-mean-square roughness over the $10 \times 10 \mu \mathrm{m}^{2}$ scans ranges between 1.2 and $1.5 \mathrm{~nm}$. The surface of the epilayer without TMIn flow in Fig. 1(a) is characterized by high density of nanometerscale surface pits (dark spots). These surface pits are associated with the surface termination of threading dislocations. ${ }^{17,18}$ As seen in the AFM images from Figs. 1(a) and 1(d), increasing the TMIn flow rate reduces the density of surface pits. This could be a result of enhanced adatom mobility of group III atoms.

Figure 2 compares the RT PL spectra corresponding to the series of epilayers shown in Fig. 1. All samples were scanned from 2 to $6 \mathrm{eV}$ to probe impurity related as well as band-edge transitions. The dominant band-edge emission peaks at $5.20 \mathrm{eV}$ of these spectra are due to the localized exciton recombination in $\mathrm{Al}_{0.75} \mathrm{Ga}_{0.25} \mathrm{~N}$ alloys. ${ }^{19,20}$ In addition to the band-edge emission peak, the emission spectra of all of these samples comprise a deep level impurity transition at $3.2 \mathrm{eV}$, which has been previously identified and was assigned to the recombination between shallow donors and cation vacancy complexes with two-negative charge, $\left(V_{\mathrm{III}}{ }^{-} \text {-complex }\right)^{2-} \cdot{ }^{21}$ There is a clear correlation between the intensity of the $\left(V_{\mathrm{III}}{ }^{-} \text {complex }\right)^{2-}$ related impurity emission 
(a) $\mathrm{TMIn}=0 \mathrm{ml} / \mathrm{min}$

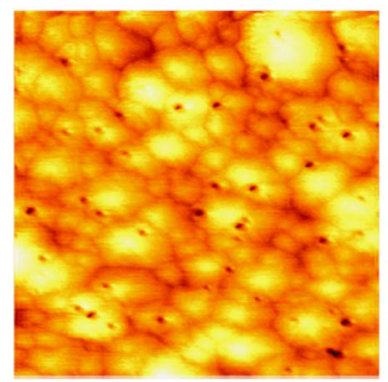

(c) $\mathrm{TMIn}=24 \mathrm{mI} / \mathrm{min}$

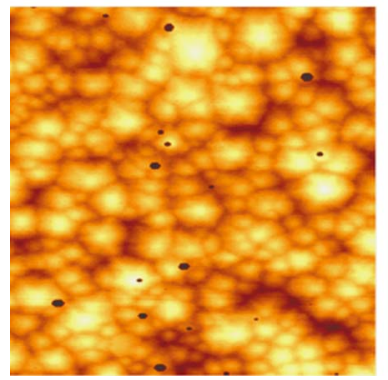

(b) TMIn $=18 \mathrm{ml} / \mathrm{min}$

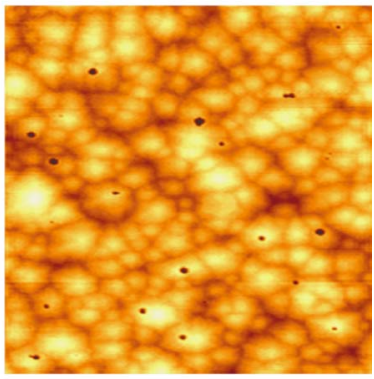

(d) $\mathrm{TMIn}=30 \mathrm{mI} / \mathrm{min}$

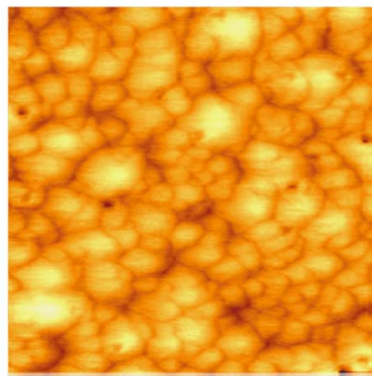

FIG. 1. (Color online) AFM images of $0.8 \mu \mathrm{m}$ thick Si doped $\mathrm{Al}_{0.75} \mathrm{Ga}_{0.25} \mathrm{~N}$ epilayers showing changes in the density of surface pits with the TMIn flow rates (a) $0 \mathrm{ml} / \mathrm{min}$, (b) $18 \mathrm{ml} / \mathrm{min}$, (c) $24 \mathrm{ml} / \mathrm{min}$, and (d) $30 \mathrm{ml} / \mathrm{min}$.

and the TMIn flow rate. Increasing the TMIn flow rate decreases the intensity of the deep level impurity transition.

Hall effect measurements reveal that the conductivity and electron concentration of Si-doped $\mathrm{Al}_{0.75} \mathrm{Ga}_{0.25} \mathrm{~N}$ increase with an increase of the TMIn flow rate. The mobility decreases slightly with increasing the TMIn flow rate. The electron concentration increase is directly related with reduced cation vacancy complexes. As shown in Fig. 2, the intensity of the deep level impurity transition at $3.2 \mathrm{eV}$ is also decreased with an increase of the TMIn flow rate, which suggests that indium as a surfactant counteracts the incorporation of $\left(V_{\mathrm{III}} \text {-complex }\right)^{2-}$ defects responsible for self-compensation in high-Al content AlGaN layers. The slight reduction of the mobility could be due to the enhanced free electron concentration. The Hall effect measurement results are summarized in Table I. The XRD rocking curves of the (002) peaks were measured. The FWHM decreases as the

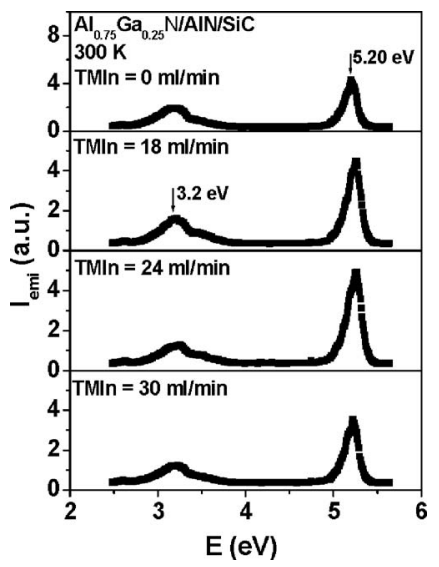

FIG. 2. RT PL spectra of $0.8 \mu \mathrm{m}$ thick $\mathrm{Si}$ doped $\mathrm{Al}_{0.75} \mathrm{Ga}_{0.25} \mathrm{~N}$ epilayers showing change in the emission intensity of the deep level impurity transition at $3.2 \mathrm{eV}$ with the TMIn flow rate. alloys with the TMIn flow rate.
Downloaded 12 Jul 2010 to 129.118 .86 .45 . Redistribution subject to AlP license or copyright; se

TABLE I. Resistivity $\rho$, electron concentration $n$, and mobility $\mu$ of Sidoped $\mathrm{Al}_{0.75} \mathrm{Ga}_{0.25} \mathrm{~N}$ epilayers as functions of the TMIn flow rate.

\begin{tabular}{cccc}
\hline \hline TMIn (ml/min $)$ & $\rho(\Omega \mathrm{cm})$ & $n\left(\times 10^{18} \mathrm{~cm}^{-3}\right)$ & $\mu\left(\mathrm{cm}^{2} / \mathrm{V} \mathrm{s}\right)$ \\
\hline 0 & 0.044 & 5.6 & 26.0 \\
18 & 0.038 & 7.3 & 24.0 \\
24 & 0.032 & 8.1 & 23.3 \\
30 & 0.027 & 9.5 & 21.1 \\
\hline \hline
\end{tabular}

TMIn flow rate increases, which indicates that the presence of TMIn improves the crystalline quality of Si-doped $\mathrm{Al}_{0.75} \mathrm{Ga}_{0.25} \mathrm{~N}$. In Fig. 3, we summarize the effects of indium surfactant on optical, electrical, and crystalline quality of $\mathrm{Si}-\mathrm{Al}_{0.75} \mathrm{Ga}_{0.25} \mathrm{~N}$ epilayers. Improvement in the overall quality of the material is evident through the observations of enhanced free electron concentration [Fig. 3(a)], reduced impurity related transition [Fig. 3(b)], and reduced XRD line width [Fig. 3(e)].

From the FWHM of the (002) XRD peak, the screw dislocation density can be estimated. ${ }^{22}$ The screw dislocation density $\left(N_{\text {screw }}\right)$ was seen to reduce from $2.18 \times 10^{8}$ to 1.12 $\times 10^{8} \mathrm{~cm}^{-2}$ as the TMIn flow rate was increased from 0 to $30 \mathrm{ml} / \mathrm{min}$. Figure 4 plots the emission intensity of the deep level impurity transition at $3.2 \mathrm{eV}$ as a function of $N_{\text {screw }}$, which clearly shows that the emission intensity of the deep level impurity transition at $3.2 \mathrm{eV}$ decreases with decreasing $N_{\text {screw }}$. Since the deep level impurity transition at $3.2 \mathrm{eV}$ is due to the recombination between shallow donors and $\left(V_{\mathrm{III}}-\mathrm{complex}\right)^{2-}$, the result thus suggests that there is a strong correlation between the concentration of $V_{\text {III }}$ (or complex) and screw dislocation density. This type of correlation has been previously observed and discussed for $\mathrm{GaN}$ epilayers. ${ }^{23-25}$

In summary, effects of using indium as a surfactant during the MOCVD growth of Si-doped $\mathrm{Al}_{0.75} \mathrm{Ga}_{0.25} \mathrm{~N}$ epilayers were investigated. It was found that as the indium flow rate increases the density of surface pits decreases and the XRD FWHM of (002) peak is narrowed, indicating a reduction in screw dislocation density. The emission intensity of the deep level impurity transition associated with cation vacancy complex $\left(V_{\mathrm{III}}{ }^{-c o m p l e x}\right)^{2-}$ was found to decrease almost linearly with a decrease of the screw dislocation density. Moreover,

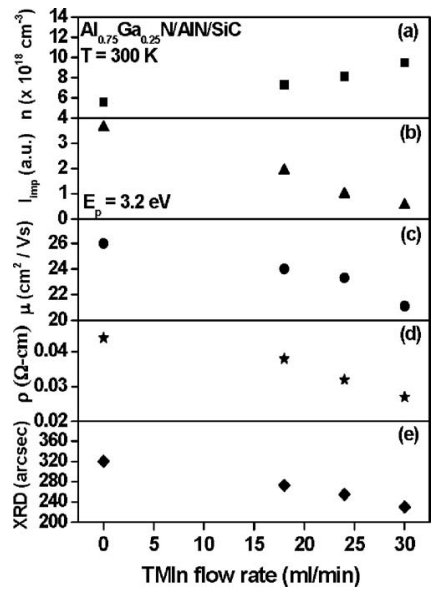

FIG. 3. Variations of the (a) electron concentration $n$, (b) intensity of the deep level impurity transition at $3.2 \mathrm{eV}, I_{\text {imp }}$, (c) mobility $\mu$, (d) resistivity $\rho$, and (e) XRD FWHM of (002) rocking curve of $\mathrm{Si}$ doped $\mathrm{Al}_{0.75} \mathrm{Ga}_{0.25} \mathrm{~N}$

alloys with the TMIn flow rate.
AIP license or copyright; see http://apl.aip.org/apl/copyright.jsp 


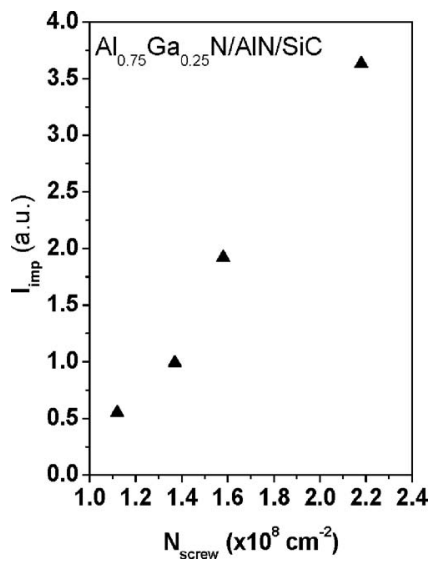

FIG. 4. Emission intensity of the deep level impurity transition at $3.2 \mathrm{eV}$ as a function of the screw dislocation density $N_{\text {screw }}$.

indium as a surfactant was also shown to increase the electron concentration and conductivity, which is directly related to the reduction of cation vacancies and their complexes.

This research is supported by a grant from DOE, Under Grant No. DE-FG03-96-ER 45604.

${ }^{1}$ Y. Taniyasu, M. Kasu, and N. Kobayashi, Appl. Phys. Lett. 81, 1255 (2002).

${ }^{2}$ M. L. Nakarmi, K. H. Kim, K. Zhu, J. Y. Lin, and H. X. Jiang, Appl. Phys. Lett. 85, 3769 (2004).

${ }^{3}$ Y. Taniyasu, M. Kasu, and T. Makimoto, Appl. Phys. Lett. 85, 4672 (2004).

${ }^{4}$ T. Ive, O. Brandt, H. Kostial, K. J. Friedland, L. Daweritz, and K. H. Ploog, Appl. Phys. Lett. 86, 024106 (2005).

${ }^{5}$ J. Neugebauer and C. G. Van de Walle, Appl. Phys. Lett. 69, 503 (1996).

${ }^{6}$ T. Mattila and R. M. Nieminen, Phys. Rev. B 55, 9571 (1997).
${ }^{7}$ C. Stampfl and C. G. Van de Walle, Phys. Rev. B 65, 155212 (2002).

${ }^{8}$ I. Gorczyca, N. E. Christensen, and A. Svane, Phys. Rev. B 66, 075210 (2002).

${ }^{9}$ K. B. Nam, M. L. Nakarmi, J. Y. Lin, and H. X. Jiang, Appl. Phys. Lett. 86, 222108 (2005).

${ }^{10}$ N. Nepal, M. L. Nakarmi, J. Y. Lin, and H. X. Jiang, Appl. Phys. Lett. 89, 092107 (2006)

${ }^{11}$ B. Pödör, Phys. Status Solidi 16, K167 (1966).

${ }^{12}$ A. Y. Polyakov, N. B. Smirnov, A. V. Govorkov, M. G. Milidivskii, J. M. Redwing, M. Shin, M. Showronski, D. W. Greve, and R. G. Wilson, SolidState Electron. 42, 627 (1998).

${ }^{13}$ P. Cantu, S. Keller, U. Mishra, and S. DenBaars, Appl. Phys. Lett. 82, 3683 (2003).

${ }^{14}$ V. Adivarahan, G. Simin, G. Tamulaitis, R. Srinivasan, J. Yang, A. Khan, M. Shur, and R. Gaska, Appl. Phys. Lett. 79, 1903 (2001).

${ }^{15}$ M. L. Nakarmi, N. Nepal, C. Ugolini, T. M. Altahtamouni, J. Y. Lin, and H. X. Jiang, Appl. Phys. Lett. 89, 152120 (2006).

${ }^{16}$ See (http://www.phys.ksu.edu/area/GaNgrou).

${ }^{17}$ X. H. Wu, P. Fini, E. J. Tarsa, B. Heying, S. Keller, U. K. Mishra, S. P. DenBaars, and J. S. Speck, J. Cryst. Growth 189/190, 231 (1998).

${ }^{18}$ P. Cantu, F. Wu, P. Waltereit, S. Keller, A. E. Romanov, U. K. Mishra, S. P. DenBaars, and J. S. Speck, Appl. Phys. Lett. 83, 674 (2003).

${ }^{19}$ H. S. Kim, R. A. Mair, J. Li, J. Y. Lin, and H. X. Jiang, Appl. Phys. Lett. 76, $1252(2000)$

${ }^{20}$ G. Coli, K. K. Bajaj, J. Li, J. Y. Lin, and H. X. Jiang, Appl. Phys. Lett. 80, 2907 (2002)

${ }^{21}$ N. Nepal, M. L. Nakarmi, J. Y. Lin, and H. X. Jiang, Appl. Phys. Lett. 89, 092107 (2006).

${ }^{22}$ B. N. Pantha, R. Dahal, M. L. Nakarmi, N. Nepal, J. Li, J. Y. Lin, and H. X. Jiang, Appl. Phys. Lett. 90, 241101 (2007).

${ }^{23}$ D. G. Zhao, D. S. Jiang, H. Yang, J. J. Zhu, Z. S. Liu, S. M. Zhang, J. W. Liang, X. Li, X. Y. Li, and H. M. Gong, Appl. Phys. Lett. 88, 241917 (2006).

${ }^{24}$ J. Elsner, R. Jones, P. K. Sitch, V. D. Proezag, M. Elsner, Th. Frauenheim, M. I. Heggie, S. Oberg, and P. R. Briddon, Phys. Rev. Lett. 79, 3672 (1997).

${ }^{25}$ D. D. Koleske, M. E. Twigg, A. E. Wickenden, R. L. Gorman, J. A. Freitas, Jr., and M. Fatemi, Appl. Phys. Lett. 75, 3141 (2000). 